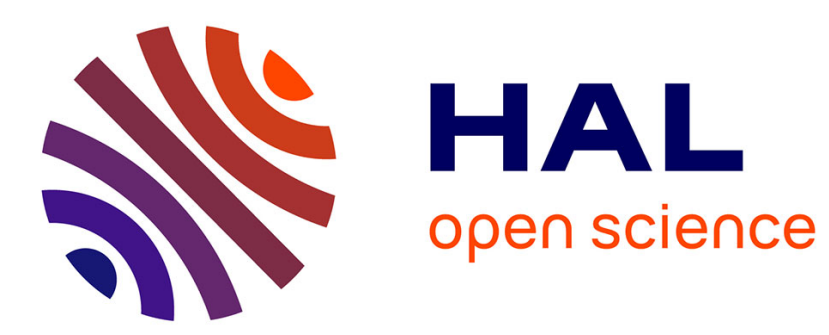

\title{
X-ray diffraction by surface acoustic waves
}

M. Brunel, D. Roshchupkin, R. Tucoulou

\section{To cite this version:}

M. Brunel, D. Roshchupkin, R. Tucoulou. X-ray diffraction by surface acoustic waves. Journal de Physique IV Proceedings, 1994, 04 (C5), pp.C5-717-C5-720. 10.1051/jp4:19945154 . jpa-00252833

\section{HAL Id: jpa-00252833 https://hal.science/jpa-00252833}

Submitted on 1 Jan 1994

HAL is a multi-disciplinary open access archive for the deposit and dissemination of scientific research documents, whether they are published or not. The documents may come from teaching and research institutions in France or abroad, or from public or private research centers.
L'archive ouverte pluridisciplinaire HAL, est destinée au dépôt et à la diffusion de documents scientifiques de niveau recherche, publiés ou non, émanant des établissements d'enseignement et de recherche français ou étrangers, des laboratoires publics ou privés. 


\section{X-ray diffraction by surface acoustic waves}

\section{BRUNEL*, D.V. ROSHCHUPKIN ${ }^{* * *}$ and R. TUCOULOU*}

${ }^{*}$ CNRS, Laboratoire de Cristallographie, BP. 166X, 38042 Grenoble cedex, France

${ }^{* *}$ Institute of Microelectronics Technology, Russian Academy of Sciences, 142432 Chernogolovka, Moscow District, Russia

résumé : X-ray diffraction on the $Y Z$ cut of a $\mathrm{LiNbO}_{3}$ crystal modulated by surface acoustic waves was investigated under the total external reflection conditions. It is shown that the characteristics of the diffracted beam are determined by the amplitude and by the period of the surface acoustic waves. This experimental study has revealed the possibility of fabricating optical instruments for space-time modulation of X-ray diffracted radiations based on the control of the wavelength of the surface acoustic waves.

\section{Introduction}

X-ray methods, such as X-ray diffraction or stroboscopic X-ray topography have been found to be very useful in the study of the physical mechanisms which rule the acoustic signal propagation in the near-crystal surface regions.

Some experiments have already been carried out concerning bulk acoustic waves [1] or X-rays diffraction of in the Bragg position on surface acoustic waves(SAW)[2]. Two works have also recently been done using an ultrasonic superlattice and X-ray diffraction under the total external reflection conditions [3-4] and outlining the main advantages of this technique: One is the high reflectivity, typically $90 \%$, the other is the effectiveness of scattering by the SAW, whose amplitude is nearly comparable to the depth of penetration of the evanescent X-ray wave, in the order of $100 \AA$.

This article presents the investigation of X-ray diffraction on an ultrasonic superlattice under the total external reflection conditions.

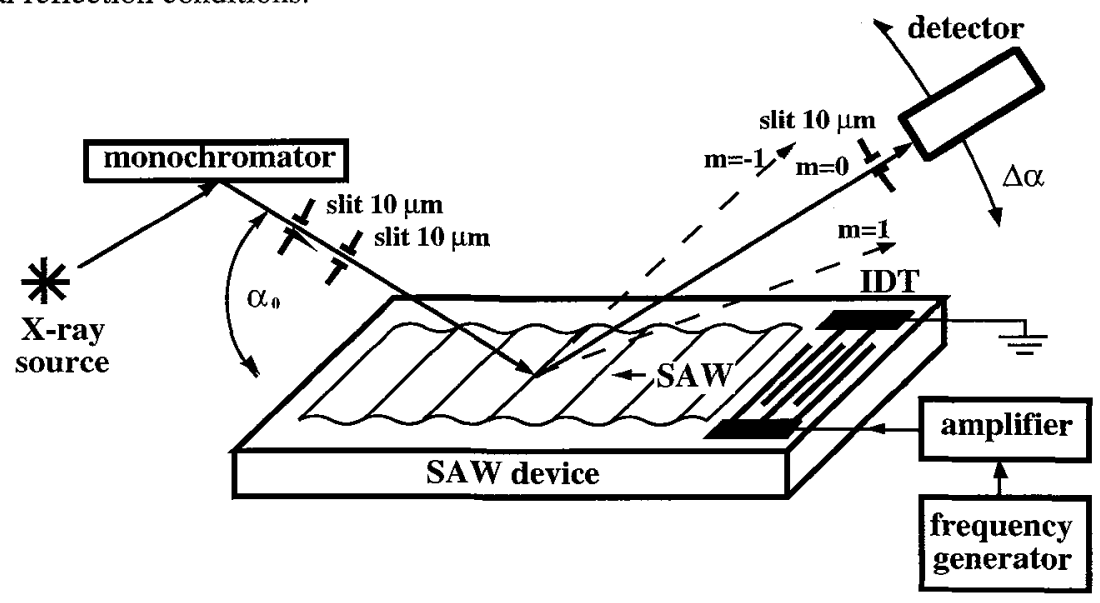

Fig. 1. Scheme of the double-crystal X-ray diffractometer. 


\section{Experimental set up}

Fig. 1 shows a scheme of the double-crystal X-ray diffractometer used to study X-ray diffraction(total external reflection) on the $Y Z$ cut of a $\mathrm{LiNbO}_{3}$ crystal modulated by SAWs. An X-ray tube with a rotating copper anode $\left(\mathrm{Cu} K_{\alpha}\right.$ radiation, $\left.\lambda=1.54 \AA\right)$ is used as a source of $\mathrm{X}$-ray radiation. An $\mathrm{X}$-ray plane wave behind a graphite crystal-monochromator is collimated by two slits of size $20 \mu \mathrm{m}$. One of these slits is placed at the focal point of the curved graphite crystal-monochromator and the other at 60 $\mathrm{mm}$ from the sample.

An interdigital transducer (IDT) with a SAW wavelength of $\Lambda=30 \mu \mathrm{m}$ was deposited on the surface of the $Y Z$ cut of the $\mathrm{LiNbO}_{3}$ crystal for $\mathrm{SAW}$ excitation. Its resonance frequency is $f_{0}=116 \mathrm{MHz}$ and its transmission band is $\Delta f / f_{0}=12 \%(f=107-121 \mathrm{MHz})$. The $\mathrm{SAW}$ velocity along the $Z$ axis of the cristal is $V=3.488 \mathrm{~km} / \mathrm{s}$.

For the experiment described here the collimated X-ray plane wave falls on the surface of the $\mathrm{LiNbO}_{3}$ crystal with an angle $\alpha_{0}=0.22^{\circ}$ whose value is slightly below the critical angle of the sample, $\alpha_{c}=0.30^{\circ}$. The $X$-ray plane wave diffracts on the SAW and gives rise to diffracted $X$-ray beams in several discrete directions defined by the expression

$$
k \cos \alpha_{m}=k \cos \alpha_{0}+m K,
$$

where $k=2 \pi / \lambda, K=2 \pi / \Lambda$ and $\mathrm{m}$ is the diffraction order. The diffracted X-ray beam is recorded by a scintillation detector with a slit size of $10 \mu \mathrm{m}$.

\section{Experimental results}

Fig. 2 shows the experimental curves of the diffracted $X$-ray intensity as a function of the detector scanning angle $\Delta \alpha$, obtained at the X-ray incident angle $\alpha_{0}=0.22^{\circ}$, and at the resonance excitation frequency of the SAW $f 0=116 \mathrm{MHz}$ and for different values of the input signal on the IDT, $U=0-17 \mathrm{~V}$. The input signal on the IDT $(U=17 \mathrm{~V})$ excites the SAW with the amplitude $h=18.7 \AA$. The diffraction satellites can be observed around the intense reflected beam.

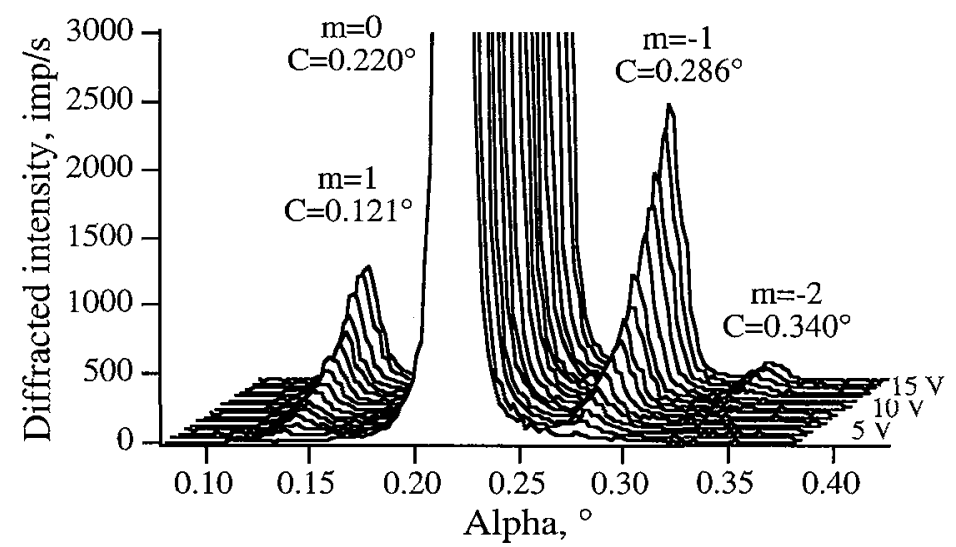

Fig. 2. Diffracted $X$-ray intensity as a function of the detector scanning angle $\Delta \alpha$, obtained at the $X$ ray incident angle $\alpha_{0}=0.22^{\circ}$, resonance excitation frequency of the SAW $f_{0}=116 \mathrm{MHz}$, and at different values of the amplitude of the input signal on the IDT, $U=0-17 \mathrm{~V}$ (C - gravity center). 


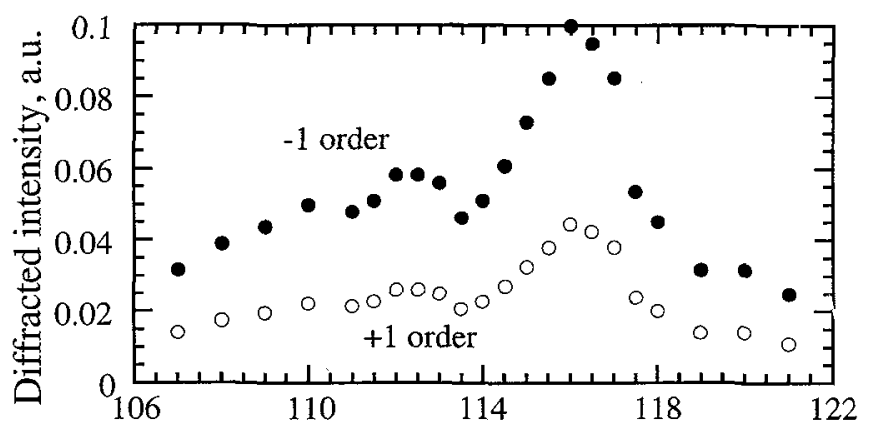

SAW frequency, $\mathrm{MHz}$

Fig. 3. Diffracted $X$-ray intensity as a function of the excitation frequency of the SAW, at an incident angle of the X-ray beam $\alpha_{0}=0.22^{\circ}$ and for an amplitude of the input si snal on the IDT $U=17 \mathrm{~V}$. The diffracted X-ray intensity is normalized to the intensity of the incident X-ray beam.

The maximum value of the diffracted intensity into the $m=-1$ diffraction order, maikes up $10 \%$ of the intensity of the incident X-ray beam and is obtained for an amplitude of the input signal on the IDT $U=17$ $V$. One can notice that the X-ray intensity which diffracts into the $m=+1$ and $m=-1$ orders, is a function of the squared amplitude of the input sinusoidal signal on the IDT (function of the squared amplitude of the SAW; see also ref. [3]). Fig. 3 represents the diffracted X-ray intensity versus the excitation frequency of the SAW $f=107-121 \mathrm{MHz}$, at an incident angle of the $X$-ray beam $\alpha_{0}=0.22^{\circ}$ and with an amplitude of the input signal on the IDT $U=17 \mathrm{~V}$. One can see that the maximum X-ray intensity diffracted into the $m=+1$, -1 orders is obtained at the resonance excitation frequency of the SAW $f_{0}=116 \mathrm{MHz}$. This is due to the fact that the maximum conversion of the electrical input signal into acoustic oscillations occurs at the resonance conditions. Fig. 4 shows the diffracted X-ray intensity as a function of the distance between the IDT and the spot on the surface. It shows that the diffracted X-ray intensity decreases with the increase of the distance from the IDT. This effect results from a damping in the substrate, which leads to decrease the amplitude of the SAW.

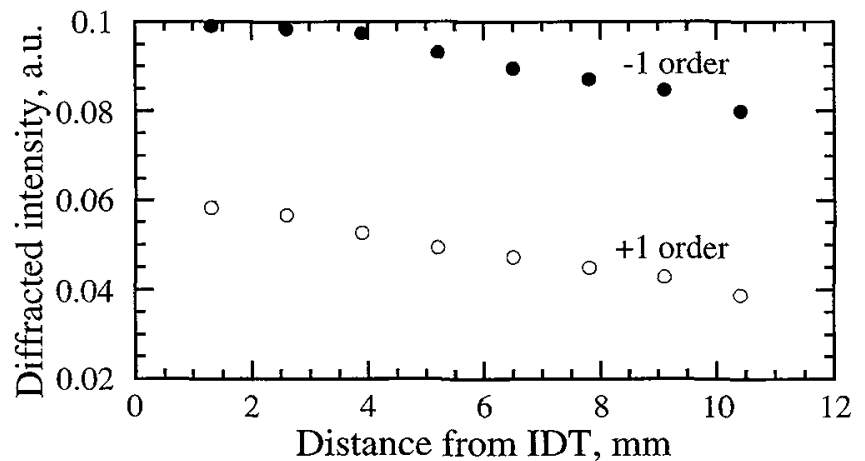

Fig. 4. Diffracted X-ray intensity as a function of the distance from the IDT, obtained at the X-ray incident angle $\alpha_{0}=0.22^{\circ}$, resonance excitation frequency of the SAW $f_{0}=116 \mathrm{MHz}$ and an amplitude of the input signal on the IDT $U=17 \mathrm{~V}$. 


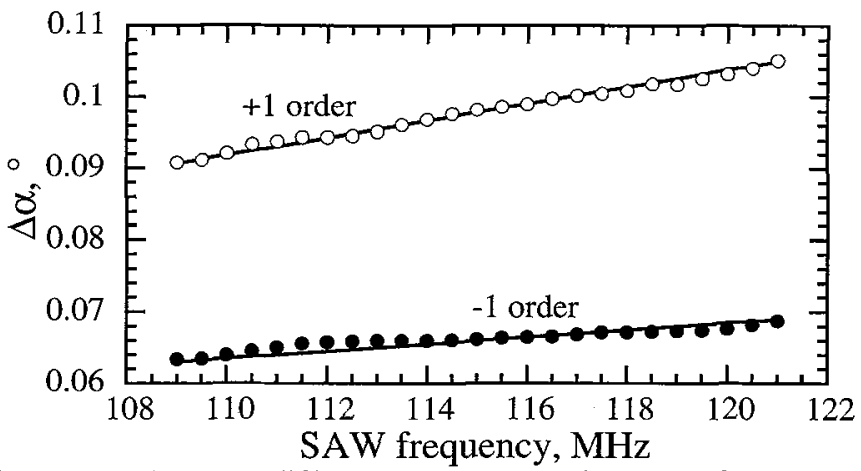

Fig. 5. Angular divergences between diffraction orders as a function of the excitation frequency of the SAW, at an incident angle of the X-ray radiation $\alpha_{0}=0.22^{\circ}$ and for an amplitude of the input signal on the IDT $U=17 \mathrm{~V}$.

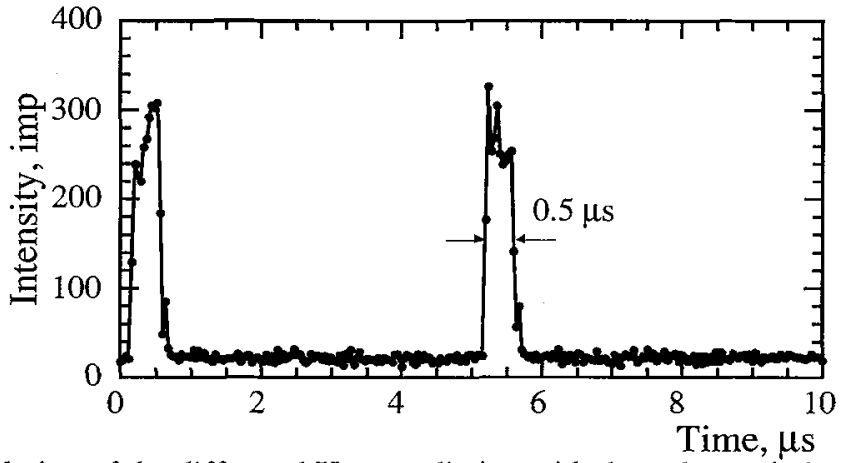

Fig. 6. Time modulation of the diffracted $X$-ray radiation with the pulse period $T=5 \mu$ s and with the pulse width $\tau=0.5 \mu \mathrm{s}$.

Fig. 5 is a plot of the angular divergence between the $-1,0,+1$ order satellites as a function of the SAW frequency. It is clear that controling the SAW excitation frequency by the input signal on the IDT enables to control this angular divergence. It seems thus rather interesting to use SAWs for X-ray beam control. Fig. 6 demonstrates the time modulation of the diffracted radiation using the pulse modulation of the SAW. In this case, the X-ray radiation diffracts into the diffraction orders only when the SAW pulses propagate across the illuminated part of the crystal.

\section{Conclusions}

The experimental investigations of X-ray diffraction on the ultrasonic superlattice under the total external reflection conditions demonstrate the real possibility to use this method for diagnostics of acoustoelectronic devices.

\section{References}

[1] I.R. Entin, Phys. Status Solidi B132, 335 (1985).

[2] S. Kikuta, T. Takahashi, and S. Nakatani, Jpn. J. Appl. Phys. 23, L193 (1984).

[3] D.V. Roshchupkin, M. Brunel, F. de Bergevin, and A.I. Erko, Nucl. Instrum. Methods B72, 471 (1992).

[4] D.V. Roshchupkin and M. Brunel, Rev. Sci. Instrum. 64, 379 (1993). 